
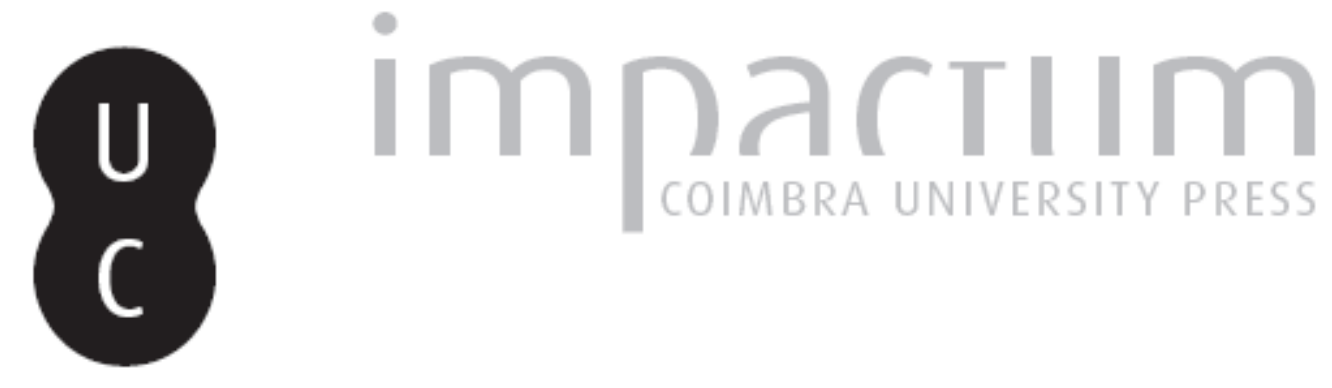

Os espetos de bronze do sudoeste peninsular: sua interpretação sócio-ideológica

Autor(es): $\quad$ Gamito, Teresa Júdice

Publicado por: Imprensa da Universidade de Coimbra

URL persistente:

URI:http://hdl.handle.net/10316.2/45608

DOI:

DOI:https://dx.doi.org/10.14195/1647-8657_25_2

Accessed : $\quad$ 26-Apr-2023 11:20:11

A navegação consulta e descarregamento dos títulos inseridos nas Bibliotecas Digitais UC Digitalis, UC Pombalina e UC Impactum, pressupõem a aceitação plena e sem reservas dos Termos e Condições de Uso destas Bibliotecas Digitais, disponíveis em https://digitalis.uc.pt/pt-pt/termos.

Conforme exposto nos referidos Termos e Condições de Uso, o descarregamento de títulos de acesso restrito requer uma licença válida de autorização devendo o utilizador aceder ao(s) documento(s) a partir de um endereço de IP da instituição detentora da supramencionada licença.

Ao utilizador é apenas permitido o descarregamento para uso pessoal, pelo que o emprego do(s) título(s) descarregado(s) para outro fim, designadamente comercial, carece de autorização do respetivo autor ou editor da obra.

Na medida em que todas as obras da UC Digitalis se encontram protegidas pelo Código do Direito de Autor e Direitos Conexos e demais legislação aplicável, toda a cópia, parcial ou total, deste documento, nos casos em que é legalmente admitida, deverá conter ou fazer-se acompanhar por este aviso. 
FACULDADE DE LETRAS

INSTITUTO DE ARQUEOLOGIA

CONIMBRIGA

$V O L U M E X X V$

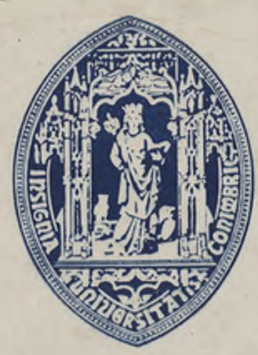

UNIVERSIDADE DE COIMBRA

1986 
TERESA JÚdice GAMITO

Professora Auxiliar da Universidade do Algarve.

Departamento de Arqueologia

OS ESPETOS DE BRONZE DO SUDOESTE PENINSULAR — SUA INTERPRETAÇÃO SÓCIO-IDEOLÓGICA

«Conimbriga», XXV (1986), 23-39

Resumo: Os espetos de bronze do Sudoeste peninsular ocorrem em duas zonas da Península Ibérica: o Sul de Portugal e o vale do Guadalquivir.

Em todo o Mediterrâneo e mais precisamente na sua zona oriental, os espetos de bronze aparecem relacionados com o culto de Hera, e como tal foram encontrados no Heraion de Samos, no Heraion de Perachora e no Heraion de Chipre, e também como consagrações a Hera e Herakles nos túmulos dos heróis. Como tal deverão ser considerados obeloi, isto é, objectos rituais onde determinados órgãos e partes da vítima sacrificada à divindade eram assados no fogo ritual e divididos entre os oficiantes durante a cerimónia religiosa.

No Sudoeste peninsular, embora na maioria dos casos os obeloi tenham sido recuperados já fora do seu contexto, há no entanto evidência arqueológica suficiente para relacioná-los com as práticas funerárias e atribuir-lhes o seu verdadeiro significado cultual. Nesse sentido procurei fazer na introdução a história da investigação e referir as suas áreas de ocorrência seguida da discussão das implicações sócio-ideológicas relacionadas com o seu aparecimento nesta região da Península Ibérica.

SUMMARY: The bronze spits occur in Southwest Iberia in two main regions: Southern Portugal and the Guadalquivir valley.

All over the Mediterranean, and more precisely in its Eastern area, the bronze spits are related to the cult of Hera. Thus 
their occurrence at the Samos Heraion, at the Perachora Heraion and at the Chyprus Heraion, or in the heroes' burials as consagrations to Hera and Herakles. As such they were, in fact, considered obeloi, that is to say, cult objects used to burn some organs and parts of the victim sacrificed to the goddess which were then shared among the people involved in the religious ceremony.

Although most of the Iberian obeloi were found already oat of their context, there is still sufficient archaeological evidence to relate them to the Southwest Iberian necropoleis, and so giving them their true meaning of obeloi.

The history of the research and the circumstances of their occurrence are described, followed by the discussion of their socio-ideological implications. 


\section{OS ESPETOS DE BRONZE DO SUDOESTE PENINSULAR - SUA INTERPRETAÇÃO SÓCIO-IDEOLÓGICA}

\section{Introdução}

Os espetos de bronze do Sudoeste Peninsular foram pela primeira vez detectados e referidos por Frei Manuel do Cenáculo em 1791. Estas magníficas peças de bronze chamaram imediatamente a atenção dos estudiosos pelas suas características próprias: são longas e finas hastes de bronze, fundidas de uma só vez, com um cabo mais ou menos complexo, apresentando geralmente uma ponta de secção rectangular, fina e aguçada. Frei Manuel do Cenáculo salientou, desde o início, a sua ocorrência em túmulos especiais que ele classificou de «generais» ou de heróis, em oposição aos outros túmulos, que os não continham, de gente necessariamente considerada comum. Cenáculo, observando a sua forma específica, denominou estes objectos de «estoques», certamente por na forma se aproximarem deste tipo de armas.

Os espetos voltaram a chamar a atenção dos arqueólogos no final do século xix, sendo referidos por Augusto Filipe Simões (1878) e Estácio da Veiga (1891), tendo porém já despertado o interesse internacional, que vemos expresso em Cartaillac (1886). Estácio da Veiga encontrou mais alguns espetos, acentuando a sua ocorrência em túmulos das famosas necrópoles do Sudoeste e salientando a decoração de tipo «hallstático» dos seus cabos. Leite de Vasconcelos retoma o interesse por estes objectos e publica todo o conjunto então conhecido (Leite de Vasconcelos 1920), mas atribuindo-lhes outra função, aquela que de facto têm: 
espetos, e chamando a atenção para peças idênticas encontradas na Etrúria.

Entretanto, o número de espetos de bronze encontrados em Portuga] aumentou e novas publicações a eles se referem como a de A. Viana e Nunes Ribeiro (1958-59).

Em Espanha, Maluquer de Motes publicou em 1958 as escavações que efectuou em El Berrueco, referindo um espeto que aí encontrou, mas com características ligeiramente diferentes, chamando a atenção para a necessidade de se distinguirem dois tipos entre estes artefactos: um de tipo hallstático, onde situou o exemplar de El Berrueco, relacionado com as culturas da Europa Central, outro do Sudoeste peninsular, ocorrendo no sul de Portugal e Espanha. Blanco Freijeiro (1963, 62) refere três exemplares encontrados em uma sepultura de Cástulo, facto extremamente importante por se tratar de uma escavação moderna, em que os espetos foram perfeitamente identificados e localizados entre os objectos que acompanhavam o defunto, fazendo portanto parte integral do ritual funerário. Idênticas circunstâncias são as referentes à sepultura junto ao santuário de Cancho Roano, em Zalamea la Serena, onde Maluquer de Motes encontrou também três obeloi numa sepultura de incineração, fazendo parte do ritual funerário. Este aspecto será novamente abordado.

Finalmente Almagro Gorbea (1974) publica o corpus dos espetos do Sudoeste Peninsular, num trabalho verdadeiramente exaustivo, relacionando-os com as necrópoles e referindo alguns novos exemplares, mas não lhes conferindo o seu verdadeiro significado de obeloi.

Posteriormente novos exemplares são encontrados e referidos como é o caso dos fragmentos encontrados em povoados: Coroa do Frade (Arnaud 1979), um povoado do Bronze Final com sinais de ocupação até cerca de 700 a.C., e no oppidum de Segóvia (Eivas) (Evans, Arnaud e Júdice Gamito, em preparação), que apresenta vestígios de ocupação desde o Bronze Final até à época romana. Os novos achados aumentaram ligeiramente o número de espetos conhecidos bem com a sua área de distribuição: Zalamea la Serena (Badajoz) (Maluquer de Motes 1981), Puntal del Llops (Bonet 1981), e aqueles adquiridos pelos Museu de Sevilha (Fernandez Gomez 1982), provavelmente oriundos daquela região, mas apresentando 
na sua maioria uma forma que os inclui entre o tipo de espetos do Sul de Portugal (x).

(1) Parece-me oportuno apresentar um breve catálogo de todos os espetos encontrados na Península Ibérica (mapa 1) até este momento, devendo ser considerados obeloi todos os do tipo do Sudoeste peninsular. Embora os espetos do tipo da Europa Central fossem também objecto de culto, as intenções e o significado com que eram usados, porém, escapam-nos:

Guimarães - 1 exemplar, tipo Europa Central

Bib.: Almagro Gorbea 1974.

Alvaiá^ere - 3 exemplares, tipo Europa Central, dos quais o mais perfeito é o apresentado na fig. 1 .

Bib.: Almagro Gorbea 1974.

Mohen 1977

Coffyn 1985.

El Berrueco - 1 exemplar, tipo Europa Central

Bib.: Maluquer de Motes 1958

Almagro Gorbea 1974.

Painho (Cadaval) - 1 exemplar, tipo Sudoeste, grupo Português

2 fragmentos de outros obeloi

Paradeiro desconhecido

Bib.: Estácio da Veiga 1891

Leite de Vasconcellos 1920

Savory 1968

Almagro Gorbea 1974.

Figueiras (Cadaval) - 1 exemplar, tipo Sudoeste, grupo Português. Segundo Almagro Gorbea, tanto este como o exemplar de Aljuber estariam anteriormente expostos no M.N.A.E. entre os materiais de Pragança.

Bib.: Leite de Vasconcellos 1920

Almagro Gorbea 1974.

Aljuber (Cadaval) - 1 exemplar, tipo Sudoeste, grupo Português

Bib.: Leite de Vasconcellos 1920

Almagro Gorbea 1974.

Estremoz (?) — apenas indicado por Savory 1968.

Évora - vários exemplares mencionados por Simões (1878) que terão sido fundidos nessa ocasião.

Peroguarda (Ferreira do Alentejo) - 1 exemplar, tipo Sudoeste, grupo

Português.

Bib.: Nunes Ribeiro 1965

Almagro Gorbea 1974. 
Almagro Gorbea (1974) situa cronologicamente os espetos no século vi a.C., embora Savory (1968) pense que o tipo português deverá ter ocorrido um pouco mais cedo no início do século vII

Beja - 3 exemplares desta zona do Alentejo, tipo Sudoeste, grupo Português; encontrados juntos por um trabalhador

Bib.: Estácio da Veiga 1891

Leite de Vasconcellos 1920

Viana e Nunes Ribeiro 1958

Almagro Gorbea 1974.

Baixo Alentejo - 3 exemplares, tipo Sudoeste, grupo Português, paradeiro desconhecido

Bib.: Estácio da Veiga 1891

Almagro Gorbea 1974.

Colecção Cenáculo — oriundos de: zona de Ourique -4 exemplares, tipo Sudoeste, grupo Português, paradeiro desconhecido.

Cola -2 exemplares, tipo Sudoeste, grupo Português

Bib.: Cenáculo 1791

Estácio da Veiga 1891

Almagro Gorbea 1974.

Herdade de Guedelhas - 1 exemplar, tipo Sudoeste, grupo Português

Bib.: Viana e Nunes Ribeiro 1958

Almagro Gorbea 1974.

Cabo de S. Vicente -1 exemplar, tipo Sudoeste, grupo Português

Bib.: Estácio da Veiga 1891

Leite de Vasconcellos 1920

Almagro Gorbea 1974.

Sul de Portugal -1 exemplar, tipo Sudoeste, grupo Português

Bib.: Leite de Vasconcellos 1920

Almagro Gorbea 1974.

Faro - 1 exemplar, tipo Sudoeste, grupo Português

Bib.: Savory 1968

Almagro Gorbea 1974.

Azougada -9 exemplares: 5 no Museu de Moura, 4 no M.N.A.E. tipo Sudoeste, grupo Guadalquivir

Os de Lisboa e a maior parte dos do Museu de Moura ainda inéditos (Judice Gamito em preparação)

Bib.: Almagro Gorbea 1974.

Safara - 1 exemplar, tipo Sudoeste, grupo Português

Bib.: Fragoso de Lima 1944

Almagro Gorbea 1974.

Coroa do Frade - apenas fragmentos

Bib.: Morais Arnaud 1979.

Conimbriga, 25 (1986), 23-39 
a.C., devido a possíveis influências da Europa Central, sugeridas pelo tipo de decoração do cabo em SSS, geralmente interpretados como representando pequenas aves, em pequenos círculos, ou ainda

Segóvia - apenas fragmentos

Bib.: Evans, Júdice Gamito e Morais Arnaud, em preparação.

Sevilha - 1 exemplar, tipo Sudoeste, grupo Português

Bib.: Almagro Gorbea 1974.

Carambolo - 3 exemplares fragmentados, tipo Sudoeste, grupo Guadalquivir Bib.: Carriazo 1973

Almagro Gorbea 1974.

El Coronil -1 exemplar, tipo Sudoeste, grupo Português Bib.: Almagro Gorbea 1974.

Penaflor -1 exemplar, tipo Sudoeste, grupo Português Bib.: Almagro Gorbea 1974.

Gástulo - 3 exemplares, tipo Sudoeste, grupo Guadalquivir Bib.: Blanco 1963.

Almagro Gorbea 1974.

Collado de los Jardines -3 exemplares fragmentados

Bib.: Alvarez-Osorio 1941

7 miniaturas votivas

Bib.: Almagro Gorbea 1974.

Lantejuela -4 exemplares, tipo Sudoeste, grupo Portugués (2 ex.), grupo Guadalquivir (2 ex.)

Bib.: Fernandez Gomez 1982.

Coria del Rio - 1 exemplar, tipo Sudoeste, grupo Portugués Bib.: Fernandez Gomez 1982.

Las Peñuelas - 1 exemplar, tipo Sudoeste, grupo Portugués Bib.: Fernandez Gomez 1982.

Utrera - 1 exemplar, tipo Sudoeste, grupo Portugués Bib.: Fernandez Gomez 1982.

Cerro de la Cabeça (Santiponce) - 3 exemplares, tipo Sudoeste, grupo Guadalquivir, embora um tenha umas pequenas alhetas laterais.

Bib.: Fernandez Gomez 1982.

Peñañor -1 exemplar, tipo Sudoeste, grupo Portugués Bib.: Fernandez Gomez 1982.

Torres Alocaz (Utrera) - 3 exemplares, tipo Sudoeste, grupo Guadalquivir Bib.: Fernandez Gomez 1982.

Ecija - 1 exemplar, tipo Sudoeste, grupo Guadalquivir Bib.: Fernandez Gomez.

Marchena - 2 exemplares, tipo Sudoeste, grupo Guadalquivir Bib.: Fernandez Gomez 1982. 
linhas paralelas ou cruzadas, associadas com algum dos motivos atrás referidos. Uma datação mais exacta relativa às necrópoles do Sudoeste poderá precisar melhor os parâmetros cronológicos da ocorrência de obeloi de bronze nesta região da Península Ibérica.

\section{Interpretação sócio-ideológica}

Os espetos de bronze surgem pela primeira vez no Mediterrâneo Oriental como objectos ligados ou associados ao culto de Hera, quer em templos, como é o caso do heraion de Samos (Samos 1969 a 1978, mais precisamente o primeiro volume; Walter 1976), ou o heraion de Perachora (Payne 1940), ou o heraion de Argos (Waldstein 1902, 61; 1905) ou nos túmulos de heróis, como consagrações a Herakles e Hera, como deusa do mundo subterrâneo. Deveriam ser usados uma só vez e depositados quer como oferenda votiva, quer acompanhando o defunto. Como tal, a sua verdadeira designação deverá ser a de obeloi.

Dechelette $(1913,797 / 804 ;$ 1914, 1415/1417) conta-se entre os primeiros arqueólogos que consideraram ser os espetos objectos de culto, e refere as suas áreas de ocorrência, além do Egeu: em Beilngries (Alta Baviera) e Etrúria, associados às culturas da Europa Central. Foram de novo claramente distinguidos por Jacobsthal (1959) como objectos de culto e diferenciados dos alfinetes de bronze, principalmente devido ao seu comprimento.

EI Coronil - 1 exemplar, tipo Sudoeste, grupo Guadalquivir Bib.: Fernandez Gomez 1982.

Alcolea del Rio - 1 exemplar, tipo Sudoeste, grupo Guadalquivir Bib.: Fernandez Gomez 1982

Puente Genii - 1 exemplar, tipo Sudoeste, grupo Guadalquivir Bib.: Fernandez Gomez 1982.

Sevilla (área) - 3 exemplares, tipo Sudoeste, grupo Português: 2 exemplares, grupo Guadalquivir: 1 exemplar Bib.: Fernandez Gomez 1982.

Cancho Roano (Zalamea la Serena) - 3 exemplares, tipo Sudoeste, grupo Guadalquivir

Bib.: Maluquer de Motes 1981

Fernandez Gomez 1982. 
Coffyn (1985, 178/179 e 224) considera os espetos de bronze originários nas culturas do Bronze Atlântico, sendo os do Sudoeste Peninsular uma versão simplificada daqueles que se encontraram a norte do Tejo — os de Alvaiázere (Fig. 1) - que apresentam grandes semelhanças com os da França ocidental. Mohen $(1977,38)$ também considera os espetos de um modo geral como originais da Europa Central, constituindo os espetos da França Ocidental um grupo separado, com a característica articulação e apoio. Tanto Mohen como Coffyn estão convencidos serem os espetos de bronze objectos de culto, relacionados com rituais funerários.

$\mathrm{Na}$ realidade, trata-se de espetos constituídos por duas partes distintas, unidas por uma espécie de articulação, sobre a qual surgem, no caso de Alvaiázere, dois pássaros e, no do depósito de Chollans (Vendée) (Mohen 1977), um veado, ambos os animais evocativos da vida de além-túmulo na mitologia céltica (Mac Cana 1983, Cunliffe 1979).

Do ponto de vista da origem destes objectos no Egeu, foi o problema novamente revisto por Kron em 1971, onde explica claramente o seu uso e significado. Também Furtwángler (1980) e Karageorghis $(1973,1980,1983)$ se dedicaram a este assunto considerando os espetos de bronze essencialmente objectos de culto, em oposição a Courbin (1983), para quem os obeloi têm apenas um valor monetário, como uma das «moedas» correntes em transacções comerciais da época. Embora, de facto, este significado existisse atribuído aos obeloi de ferro, estes também aparecem nos templos, ganhando aí não só o seu significado votivo mas também o de oferenda valiosa.

No Sudoeste peninsular, os obeloi de bronze também aparecem associados a cultos religiosos e rituais funerários, ocorrendo essencialmente em duas áreas de distribuição (mapa 1), podendo assim distinguir-se, dentro do tipo característico do Sudoeste, dois grupos:

1) O grupo português penetrando desde a costa do Algarve até ao Baixo Alentejo e Extremadura espanhola, seguindo uma linha oblíqua, com alguns casos na zona de Sevilha;

2) O grupo do Guadalquivir, ao longo do vale do mesmo nome, mas atingindo ainda a margem esquerda do Guadiana, na 
região do Castro de Azougada. Neste grupo incluem-se alguns exemplares com o cabo característico da zona, mas com pequenas e estreitas alhetas laterais, aproximando-se assim do grupo Português.

Algumas características externas definem estes dois grupos de obeloi:

a) os portugueses são longas barras de bronze (apenas dois são feitos de cobre), com cerca de $1,10 \mathrm{~m}$ de comprimento (podendo atingir no seu comprimento máximo $1,15 \mathrm{~m} \mathrm{e} 0,80 \mathrm{~m}$ ou mesmo 0,60 m, no seu comprimento mínimo). Ainda se distinguem por apresentarem um cabo com elaboradas decorações e com umas pequenas alhetas laterais, separando o cabo da lâmina. A decoração é variável, podendo apresentar efeitos com traços paralelos, linhas entrecruzadas, pequenos círculos ou sucessões de SSS (Fig. 2);

b) os exemplares espanhóis do Guadalquivir são muito mais simples e curtos, geralmente com o comprimento máximo de cerca de 0,60 m, e o cabo destingue-se da lâmina apenas por apresentar um leve espessamento espalmado, sem qualquer decoração. Os exemplares do Castro de Azougada são perfeitamente idênticos aos do Guadalquivir (Fig. 3), apenas um apresenta uma notável semelhança com os exemplares de Samos publicados por Furtwángler (1980, 84 e 88). De salientar que o Castro de Azougada apresentou maior número de obeloi encontrados juntos, tendo sido, infelizmente, recolhidos em uma escavação da responsabilidade do Prof. Manuel Heleno que ficou por publicar, desconhecendo-se, assim, o seu contexto e localização estratigráfica (Júdice Gamito, em preparação).

Todos os exemplares espanhóis são feitos de bronze.

Os obeloi do Sudoeste peninsular, diferentes na forma dos exemplares atlânticos, apareceram geralmente associados aos rituais funerários nas chamadas «necrópoles do Sudoeste», famosas pelas suas inscrições ainda por decifrar. Tal é o caso da necrópole do Castro da Cola (Ourique) (Cenáculo 1791) e de Cástulo (Jaén) (Blanco 1963; Almagro Gorbea 1974) e do túmulo de Cancho Ruano (Zalamea la Serena) (Maluquer de Motes 1981, 1982; Fernandez Gomez 1982), ou em santuários, como oferendas votivas, como é o caso de Collado de los Jardines (Jaén) (Almagro 
Gorbea 1974, Cancho Roano (Zalamea la Serena, Badajoz) (Maluquer de Motes 1981) e provavelmente na zona de Sagres (Faro) (Estácio da Veiga 1891), considerada pelos autores antigos como área de carácter sagrado (Avienus, Ora Mar., 322, 334; Strabo, Geog., III, 8). Os outros espetos foram encontrados em povoados, como é o caso da Coroa do Frade (Évora), Segóvia (Eivas), Azougada (Moura), Carambolo (Sevilha), Coronil (Sevilha), Peñaflor (Sevilha), mas provavelmente associados a rituais religiosos e áreas de culto.

Um novo espeto foi recentemente referido por Beirão (Beirão e Gomes) no que chamaram «o pequeno povoado de Fernão Vaz», por aí terem encontrado evidência de edifícios, fragmentos de cerâmica de uso comum, como grandes recipientes de largo bocal e um jarro de pequenas dimensões, e ainda um machado calcolítico com vestígios de reutilização (apresenta um orifício aberto no topo), e o espeto de bronze. (Todos estes objectos constavam da exposição do MNAE, 1980).

Uma visita ao local (mapa 2) levou-me a levantar a hipótese de ali, ou nas imediações, ter existido um altar ou pequeno templo, onde o culto de Hera ou outro culto idêntico fosse praticado. Tal hipótese baseia-se nas seguintes observações:

a) As características topográficas daquela zona da margem direita do rio Mira: na maior elevação, entre duas curvas do rio que corre célere em direcção ao mar, encontram-se os vestígios de um sítio arqueológico, com restos de muros de pedra solta, designado por Beirão como pequeno povoado da Cascalheira, cujo acesso é feito por um antigo caminho de campo assinalado na folha 563 da Carta Militar de 1952, na escala de 1:25.000 (mapa 2, a), e que o liga à necrópole de Fernão Vaz (Mapa 2, b), que se avista a curta distância e que é constituída por duas partes simétricas divididas por esse mesmo caminho, também assinalado na referida carta militar (fig. 4), e que, posteriormente, terá sido preterido pelo caminho de alternativa que contorna a necrópole pelo lado norte.

$\mathrm{Na}$ verdade, nota-se aqui, além da flagrante simetria, um grande túmulo circular, seguindo a tradição dos túmulos do final da Idade do Bronze, do tipo Atalaia, rodeado e integrado num conjunto de túmulos rectangulares característicos da Idade do 
Ferro no Sudoeste peninsular, e ainda a evolução e continuidade das populações habitando esta região do Sul de Portugal, expressa nos seus túmulos.

As duas partes da necrópole foram consideradas como dois «territórios opostos» (comunicação pessoal de Varela Gomes e também de M. Alves Dias), exactamente marcados e delimitados pelas duas partes da necrópole. Penso, no entanto, que o significado da simetria e divisão da necrópole é salientar o caminho ritual em direcção ao rio, onde teriam lugar outros rituais de purificação subsidiários daqueles realizados junto ao altar e que seriam ainda assinalados pela presença de outra necrópole mais abaixo, designada por Beirão e Gomes por «povoado de Fernão Vaz»(2) (Mapa 2, c), situado sob os vestígios do pequeno «monte» medieval.

Esta é a disposição de todos os outros heraia: com efeito o heraion de Samos apresenta uma disposição semelhante dos locais de rituais sagrados (Samos, 1969 a 1978; Walter 1976): a zona do templo ou do altar sobre uma elevação e sepulturas e oferendas votivas em ambos os lados do caminho que se dirige para o mar ou

(2) Sob os vestígios de um pequeno 'monte' medieval ou de época mais recente, Beirão localizou um sítio arqueológico que denominou «povoado da Idade do Ferro», e cuja planta e cortes apresentou na exposição do Museu Nacional de Arqueologia e Etnologia intitulada: «A Idade do Ferro no Sul de Portugal», em finais de 1980, respectivamente indicados pelos números 275 a 279. Os vestígios da Idade do Ferro encontram-se num fino estrato, sob várias camadas de abandono e do próprio 'monte' medieval. Os muros deste cortam o estrato da Idade do Ferro, aspecto que era também visível na planta do sítio arqueológico, mostrando assim tratar-se de construções posteriores. Naquela planta notava-se ainda a particularidade de, sob os muros medievais, se notarem nitidamente vestígios de construções redondas, perfeitamente nítidas no lado SW da planta (n. 277 do catálogo da exposição). Pessoalmente tive ocasião de observar no local esta mesma particularidade. Parece-me que se está perante uma necrópole da Idade do Bronze Final/Idade do Ferro Inicial, que vai precisamente aparecer representada no fino e bem delimitado estrato da Idade do Ferro, registado nos cortes da escavação. Julgo, portanto, que se trata de uma necrópole, onde eventualmente se encontrou o espeto (não pessoalmente encontrado por Beirão, mas sim retirado anteriormente) sobre a qual, em épocas posteriores, se construiu o pequeno 'monte' medieval. Admito, no entanto, a hipótese da existência de outras construções, além desta última necrópole, integradas no conjunto de locais de culto a Hera/Ataegina, na zona de Fernão Yaz. 
para o rio próximo, como é também o caso do heraion de Perachora (Payne 1940, 257), e do heraion de Argos (Waldstein 1902-1905). Este aspecto é também referido por Kron (1971, 132/98).

b) Os materiais arqueológicos incluem também recipientes de cerâmica que poderiam ter sido utilizados nos rituais de purificação dos oficiantes e, igualmente, para recolher $\mathrm{o}$ sangue $\mathrm{e}$ as partes do corpo da vítima estabelecidas no ritual. A presença de um obelos de bronze é geralmente considerada em todo o mundo mediterrâneo durante os séculos viu e vII a.C., como reflectindo propósitos sagrados, e o machado calcolítico com vestígios de reutilização poderia servir para matar o animal oferecido em sacrifício à divindade em questão.

E interessante chamar a atenção para $o$ facto de as datas mais antigas para estas necrópoles serem os séculos vil e vi a.C., com uma possível continuação durante $\mathrm{o}$ século $\mathrm{v}$ a.C., com base na ocorrência de algumas fíbulas penanulares ibéricas, de acordo com a cronologia proposta por Cuadrado (1957) $\left(^{3}\right)$.

c) Hera estava também associada à vaca, com os seus grandes olhos hipnóticos. Algumas representações da deusa foram, por vezes, feitas por meio da representação de uma vaca de barro, (mais pormenores em JÚdice GAMito 1987). Beirão também encontrou um vaso representando uma vaca na necrópole da Fonte Santa (Ourique) (Beirão e Gomes 1980, p. 23, n. 186b), situada na mesma área e apresentando as mesmas características que não diferem muito da vaca de barro do heraion de Samos (Samos 1969; Walter 1976).

$\mathrm{Na}$ krater de figuras vermelhas de Alcácer do Sal, próximo da cena do sacrifício, na qual a sacerdotisa usa três obeloi, vê-se no canto direito a cabeça de urna vaca, como se à distância estivesse presidindo à cerimónia (figs. 5 e 6). Penso que o culto

(3) Na realidade, as fíbulas penanulares ibéricas são os elementos mais tardios e de datação relativa segura que aparecem no espólio destas necrópoles. Por enquanto não se possui ainda qualquer datação absoluta para as necrópoles do Sudoeste, embora um projecto de datações de ${ }^{14} \mathrm{C}$ esteja em curso, da responsabilidade da autora e de Luís Coelho e Manuela Alves Dias, com a colaboração do Laboratório do British Museum, o que permitirá talvez obter uma ideia mais precisa sobre os parâmetros cronológicos destas necrópoles. 
representado neste vaso poderá ser o culto de Hera e não exactamente o de Apolo, como Rocha Pereira (1962, 76) sugeriu. $\mathrm{O}$ número de três parece também ser o indicado neste tipo de sacrifícios, sendo exactamente esse o que aparece depositado nos túmulos de Cástulo (Blanco 1963) e de Cancho Roano (Maluquer de Motes 1981).

d) Por outro lado, o culto de Hera encontrava-se também sempre associado à renovação anual da natureza e a cultos vegetativos. Neste sentido foi, por vezes, identificado com o culto de Perséfona (Kron 1971, 124), adquirindo, mais tarde, os aspectos negativos deste mesmo culto. $\mathrm{Na}$ época romana, também se observou que ao culto de Juno, a deusa romana correspondente a Hera, se associou o culto de Prosérpina. Em toda esta área do Sudoeste peninsular um cuito idêntico é conhecido dedicado a Ataegina, um culto céltico, como o próprio nome da deusa sugere (Leite de Vasconcelos 1905; Schmidt 1957; Blázquez 1975), cujos atributos são os mesmos de Hera. $O$ culto a Ataegina persistiu até à época romana e também ele foi associado ao culto de Perséfona e, mais tarde de Prosérpina.

e) Os autores antigos dão-nos, ainda, notícia de que no Sudoeste peninsular o culto de Juno/Hera prevaleceu entre a população indígena mesmo quando a religião «oficial» tinha mudado. É interessante salientar que Plínio refere um culto indígena dedicado a Juno (a deusa equivalente a Hera no panteão romano) em Gades:

«vocatur ab Ephoro et Philistide Erythea, a Timaeo et Sileno Aphrodisias ab indigenis Junonis» (Plinio, 4, 120).

facto que aparece também mencionado em Éscimno (153) e Estêvão de Bizâncio.

Um templo dedicado a Hera/Juno, situado perto da moderna Trafalgar, também foi mencionado por Ptolomeu (2.4.5) e Mela, que diz exactamente:

«Tum Mellaria, et Belo, et Besippo usque ad Junonis promontorium oram freti occupat» (Mela, 2. 6,9).

Avieno (205-211 e 241-244) refere um culto semelhante perto do Promontorium Sacrum (Sagres) e na cidade de Herbi (La Rabida, 
Helva), associando-o ao culto da deusa infernal, portanto Ataegina/ /Prosérpina:

«lugum inde rursus et sacrum infernae deae

divesque fanum, penetrai abstrusi cavi

adytumque caecum, multa propter esi palus

E[t]rebea dicta, quin et Herbi civitas» (Avienus, 241-244).

Schulten também associa este culto aqui referido por Avieno com o de Ataegina (Schulten 1922, 97-99).

Abel Viana e Nunes Ribeiro (1958-59) dão notícia de uma inscrição romana dedicada a Juno na zona de Beja.

$\mathrm{O}$ facto de estes espetos de bronze ocorrerem, na sua maioria, nesta zona da Península Ibérica, exactamente a área onde se situaria Tartessos e a sua zona periférica, com a qual mantinha estreitas relações (Júdice Gamito 1984) e onde possivelmente se deram também os primeiros contactos com povos de origem grega que aportaram à Península, aspectos já referidos noutra publicação (Júdice Gamito 1985) e onde concluía, o que parece ser confirmado aqui, que deveria ter havido uma fixação de gregos orientais no Sudoeste peninsular, simultânea ou anterior à dos primeiros fenícios. Este aspecto é ainda reforçado pelo facto de serem exactamente esses gregos aqueles que maior devoção dedicavam a Hera, nomeadamente os Sâmios, os Eubeus e os Fócios. Talvez uma intensificação das pesquisas no campo linguístico, neste sentido, possa produzir resultados do maior interesse cultural.

Todos estes pontos aqui referidos sugerem que muito possivelmente se deu no Sudoeste peninsular um caso de assimilação de cultos religiosos. Os atributos idênticos de Hera (Juno) e Ataegina (ambas posteriormente identificadas com Perséfona ou Prosérpina), portadores do mesmo conteúdo ideológico e social, facilitaram um processo de aculturação, incrementado pelo íntimo contacto de povos, usando objectos semelhantes, relacionados com rituais funerários e religiosos idênticos.

Agradecimento: Gostaria de expressar o meu agradecimento ao Professor Anthony Snodgrass pelo interesse que sempre manifestou por este ponto da minha investigação, e pelo encorajamento na pesquisa de mais detalhes e à Fundação C. Gulbenkian cuja bolsa me permitiu efectuar esta investigação em Cambridge. 


\section{BIBLIOGRAFIA}

Almagro Gorbea, M., 1974, Los asadores de bronce del Suroeste peninsular, «Rev. Arch. Bib. Mus.», LXXVII, Madrid, 351-395.

Del Амо, M., 1976, Restos materiales de lo: población romana de Onuba, «Huelva Arqueológica», II, Huelva.

Alvarez-Osório, F., 1941, Catalogo de los exvotos de bronce ibéricos, Madrid.

Arnaud, J. E. Moráis, 1979, Coroa do Frade, «Madrider Mitteilungen», 20, Heidelberg.

Beirão, C. M., e M. V. Gomes, 1980, A Idade do Ferro no Sul de Portugal, epigrafía e cultura, Catálogo da Exposição do Museu Nacional de Arqueologia e Etnografía, Lisboa.

Blanco Freijeiro, A., 1963, El Ajuar de una. tumba de Cástulo, «A.E.A.», XXXVI, Madrid.

Blazquez, A. M., 1975, Dicionário de las Religiones Prerromanas de Hispania, Madrid, Istmo.

Bonet, H. et alii, 1981, El poblado ibérico del Puntal dels Hops (El Colemnar, Ulocan, Valencia), «S.P.P.», Valencia.

Cartaillac, E., 1886, Les Ages Prehistoriques de VEspagne et du Portugal, Paris.

Cenáculo, Freí M. Do, 1971, Cuidados Leterários do prelado de Beja, Évora.

Cofyn, A., 1985, Le Rronze Final Atlantique dans la Peninsule Ibérique, Bordeaux, C.N.R.S.

Courbin, P., 1983, Obeloi d'Argolide et d'ailleurs, «The Greek Renaissance», Stockolm.

CuAdrado, E., 1957, La fibula anular hispánica y sus problemas, «Zephirus», VII, Salamanca, 5-76.

Cunliffe, B., 1979, The Celtic World, London, The Bodlen Head.

Dechelette, J., 1913，1914, Manuel d'Archaeologie prehistorique et Gallo-Romaine, 2. et 3. parties, París.

Estácio da Veiga, S. P. M., 1891, Antiguidades Monumentais do Algarve, v. IV, Lisboa.

Evans, J., T. Júdice Gamito, .J E. Morais Arnaud, Segovia Oppidum - excavation campaign 1972.

Fernandez Gomez, F., 1982, Nuevos asadores de bronce en el Museo Arqueológico de Sevilla, «Trabajos de Prehistoria», 39, Madrid, 389-410.

Fragoso de Lima, J., 1944, Aparecimento de um estoque de cobre ou bronze na freguesia de Safara, «Jornal de Moura», 3 de Junho de 1944.

Furtwãngler, A, E., 1980, Zur Deuting der Obeloi im Lichte samischer Neufunae, «Tania», Mainz, 81-97.

Јасов тынац, P., 1959, Greek Pins, Oxford, Univ. Press.

JÚDICE GAMIto, T., 1984, Ethnohistory: the ancient authors' reports on Southwest Iberia — an example, «Archaeological Review From Cambridge», 3:2, Depart, of Archaeology, Univ. of Cambridge.

Conimbriga, 25 (1986), 23-39 
Júdice Gamito, T., 1985, The wind of change blows from the East - Socioeconomic complexity in 6TT Iberia, «The transition from Late Bronze Age to Iron Age in Europe», Oxford (in press).

Júdice Gamito, T., (em preparação), O Castro de Azougada, Monografias MNAE, Lisboa.

Júdice Gamito, T., 1987, Os obeloi de bronze do Sudoeste Peninsular- seu contexto e interpretação sócio-ideológico, Cong. Nac. de Historia Antiga, Santiago de Compostela.

Karageorghis, V. M., 1973, Pikes or obeloi, from Cyprus and Crete, «Antichita Cretesi», 12, 168-172.

Karageorghis, V. M., 1980, Fouilles à Vancienne Paphos de Chypre: les premiers colons grecs, "Comptes rendues Ac. Insc. Belles Lettres», Paris, 122-136.

Karageorghis, V. M., 1983, Palaepaphos- Skates, an Iron Age cèmetery in Cyprus, «D.A.I.», Univ. Verlag Konstanz.

Kron, U., 1971, Zum Hypogaum von Paestum, «Jahrd. Rom. Germ. Z. Muzeums Mainz», Berlin, 117-148.

Leite de Vasconcellos, J., 1897, 1905, 1913, Religiões da Lusitania, Lisboa, Imp. Nacional.

Leite de Vasconcellos, J., 1920, Historia do Museu Etnológico Português, Lisboa.

MaC CANA, P., 1983, Celtic Mythology, Jugoslávia, Newnen.

Maluquer de Motes, J. N., 1958, Excavaciones en el Cerro d'El Berrueco (Salamanca), Universidad de Salamanca.

Maluquer de Motes, J. N., 1981, El Santuário Protohistorico de Zalamea la Serena, Badajoz, Universidad de Barcelona.

MaluQUer De Motes, 1982, Notas de arqueologia Extremeña. Los asadores de bronce del yacimiento de Cancho Ruano, en Zalamea la Serena (Badajoz), «Homenaje a Concepción Fernandez Chicarro y de Dios», Madrid.

Монеn, J.-P., 1977, Broches à rotir articullées de Vàge du Bronze, «Ant. Nat.», 9, 34-39.

Nunes RiBeiro, F., 1965, O bronze meridional português, Beja.

Payne, H., 1940, Perachora, 2 v., Oxford, T. J. Dubabin.

Rocha Pereira, M. H., 1962, Greek Vases in Portugal, Univ. Coimbra.

S A мо s, 1969 a 1978, 14 v., «Deutsches Arch. Institut», Berlin.

S avory, H. N., 1968, Spain and Portugal, London, Thames and Hudson.

Sснмірт, K. ID, 1957, Die Komposition in gallishen Personnennamen, «Zeitschrift für Celtische Philologie», 26, 31-301.

S гмõ Es, A. F., 1878, Introdução à Archeologia doi Peninsula Ibérica, Lisboa.

Schult en, A., 1922, Fontes Hispaniae Antiquae, v. I, Barcelona.

Viana, A., e F. Nunes Ribeiro, 1958-59, Notas históricas e etnográficas do Baixo Alentejo, «O Arquivo de Beja», Beja.

Waldstein, Ch., 1902 e 1905, The Argive Heraeum, 2 v., Boston, The Riverside Press.

W Al te R, H., 1976, Das Heraion von Samos, München. 


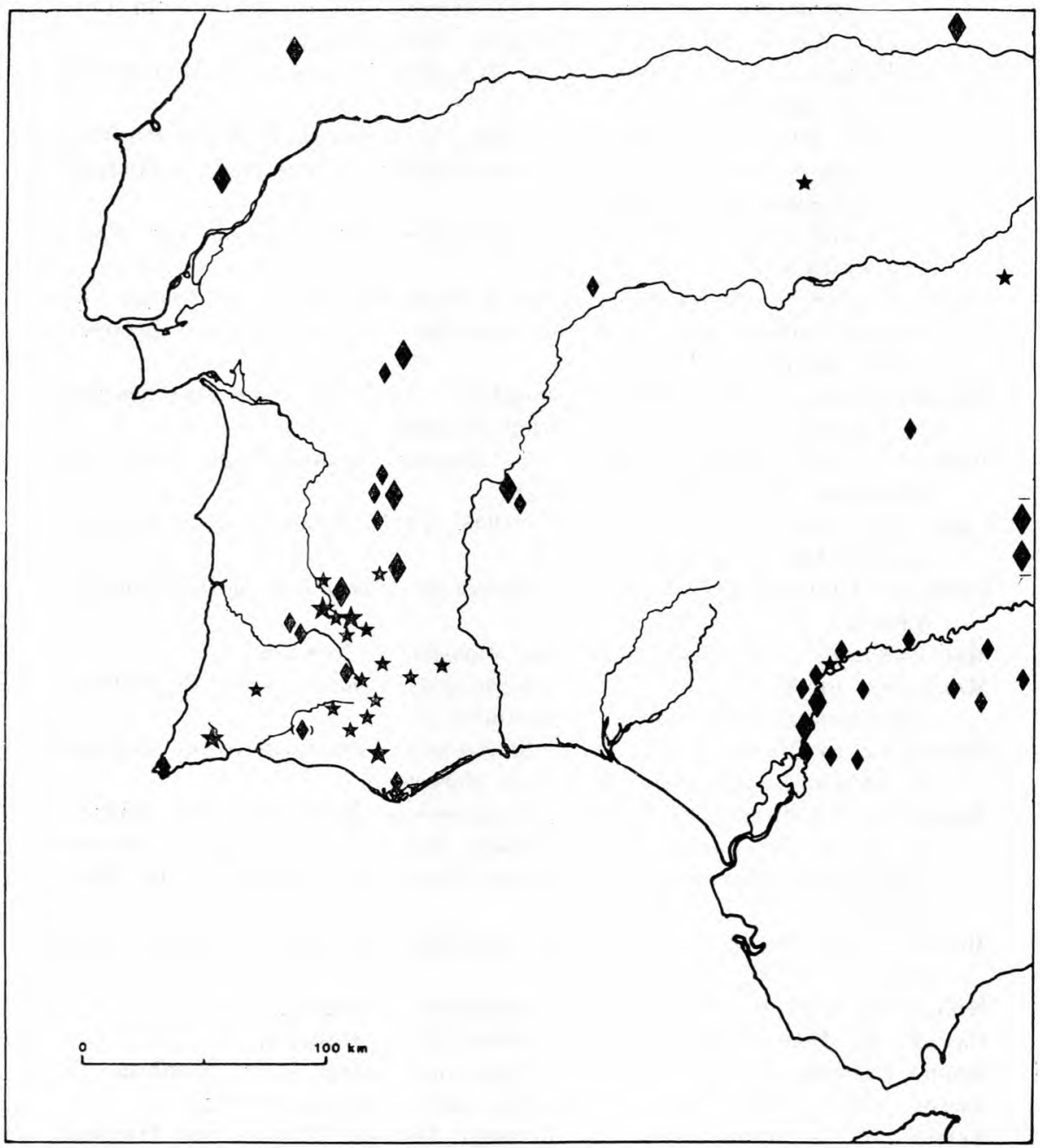

* 1 estela epigrafada do Sudoeste

* 2 ou mais exemplares

Peninsular

- 1 obelos de bronze

2 ou mais obeloi

MapA 1 -Distribuição dos obeloi e das estelas epigrafadas do Sudoeste peninsular. 


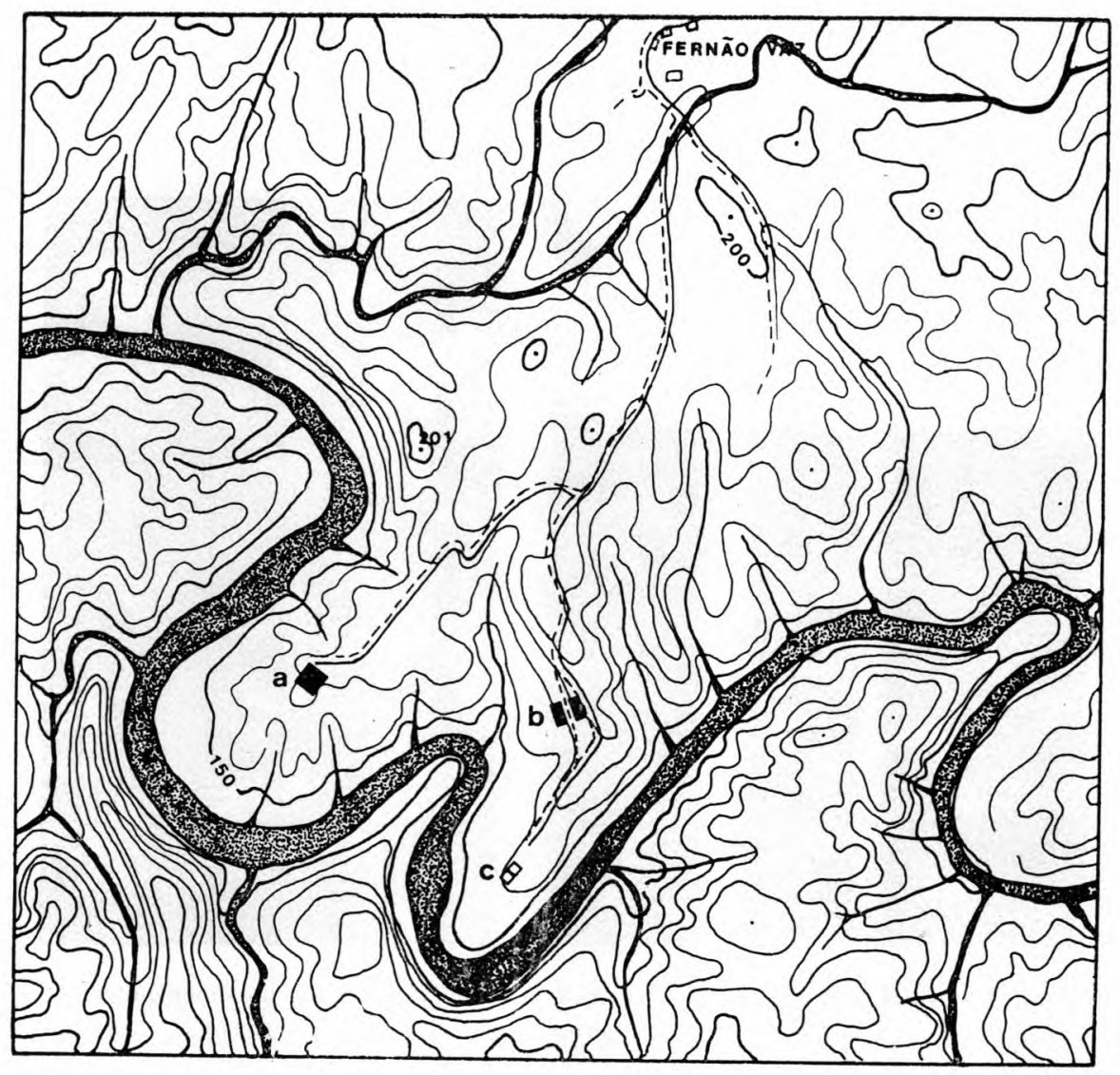

MAPA 2 - Área de Fernão Vaz, baseado na carta militar 1:25.000, N. 563 - Zonas a, b e c. 


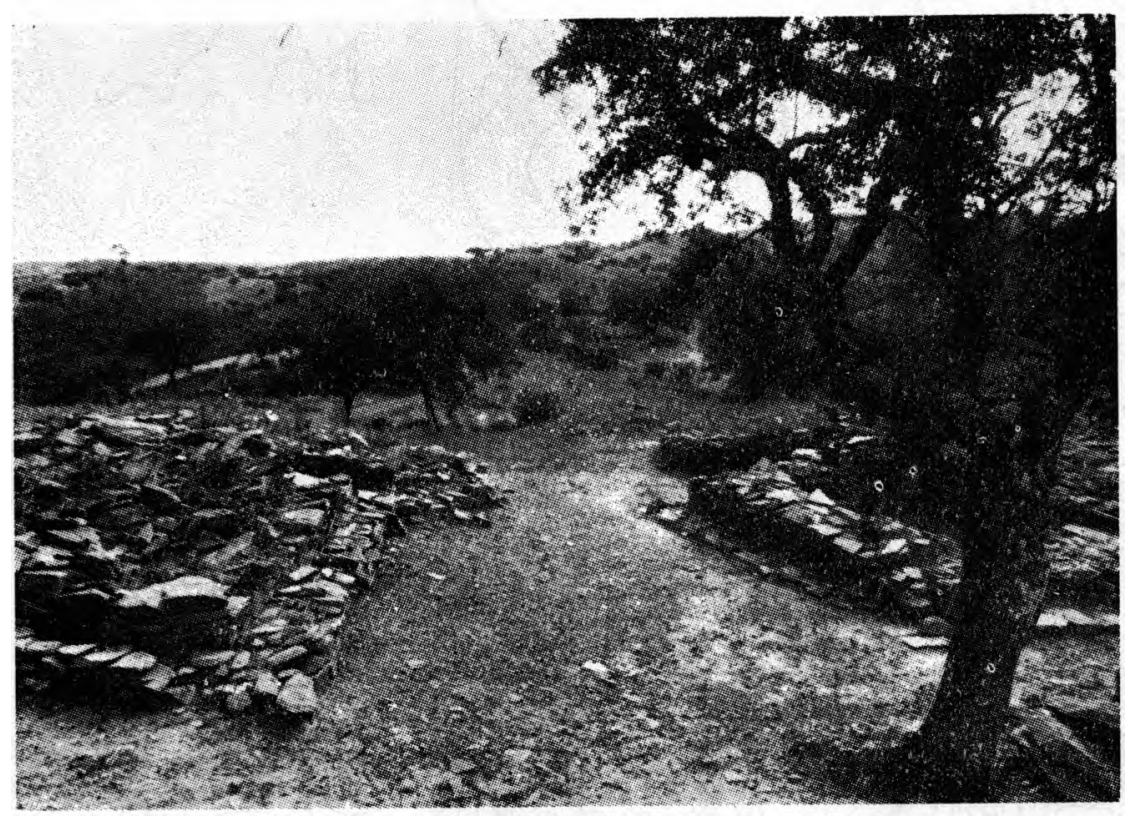

FIG. 4 - Caminho separando as duas partes simétricas da necrópole de Fernão Vaz. 


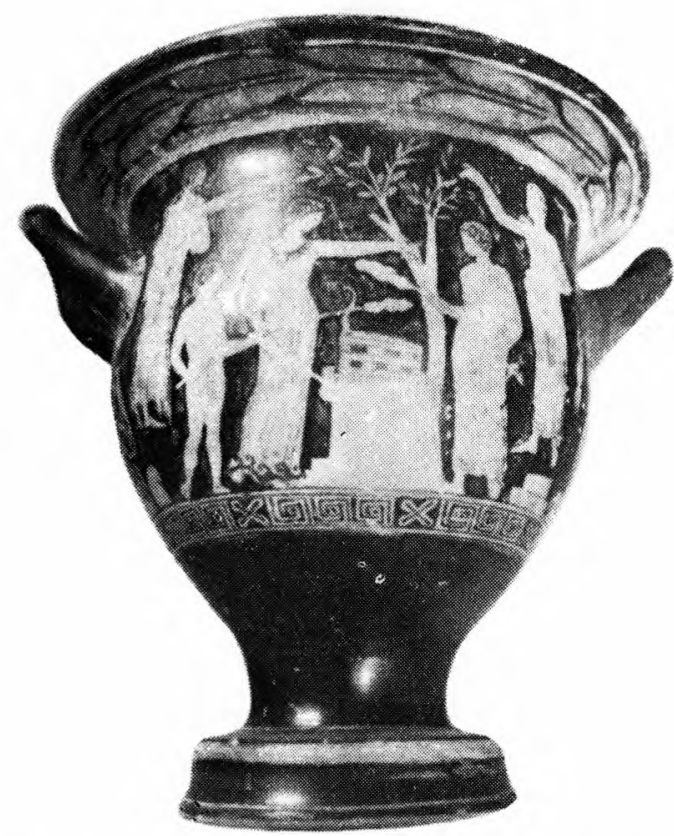

Fıg. 5-Krater de figuras vermelhas de Alcácer do Sal: a sacerdotisa oficiando usa très obeloi. No canto superior direito, a cabeça de uma vaca (do Museu Nacional de Arqueologia e Etnologia).

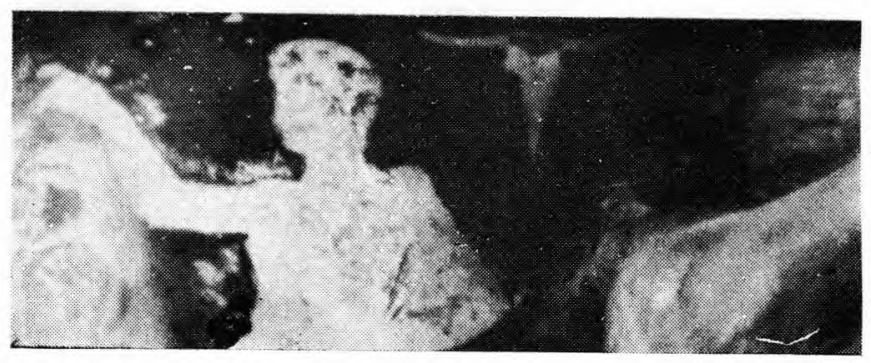

Fig. 6-Pormenor do vaso anterior. 